九州大学学術情報リポジトリ

Kyushu University Institutional Repository

\title{
The Modification of Carboxyl Group of Lysozyme
}

Hayashi, Katsuya

Laboratory of Biochemistry, Department of Agriculture, Kyushu University

Kugimiya, Masayuki

Laboratory of Biochemistry, Department of Agriculture, Kyushu University

Shimoda, Tadahisa

Laboratory of Biochemistry, Department of Agriculture, Kyushu University

Matsumoto, Nobuya

Laboratory of Biochemistry, Department of Agriculture, Kyushu University

他

https://doi.org/10.5109/22813

出版情報: 九州大学大学院農学研究院紀要. 17 (1)，pp. 1-11，1972-08. Kyushu University バージョン：

権利関係 : 


\title{
The Modification of Carboxyl Group of Lysozyme
}

\section{Katsuya Hayashi, Masayuki Kugimiya, Tadahisa Shimoda, Nobuya Matsumoto and Masaru Funatsu}

\author{
Laboratory of Biochemistry, Faculty of Agriculture, \\ Kyushu University, Fukuoka
}

(Received December 5, 1971)

\begin{abstract}
Lysozyme molecule contains eleven carboxyl groups which can be classified by the titration behavior into four types, not titratable, with low $\mathrm{p} K$-value, normal and with extraordinary high $\mathrm{p} K$-value. Furthermore, X-ray crystallographic studies revealed that each carboxyl group can be characterized by the accessibility to the surrounding medium according to its position in the molecule in the crystalline state. The present experiments were carried out to clarify a correlation between a chemical reactivity and the physical state of the carboxyl groups by modifying them with condensing reagent carbodiimide and glycine derivatives. The results indicated that at low extent of the modification carboxyl groups were selectively modified, i.e., several carboxyl groups can be distinguished by their chemical reactivities.
\end{abstract}

\section{INTRODUCTION}

The catalytic groups, Glu-35 and Asp-52, of lysozyme have been indicated by means of a physical technique, X-ray diffraction by Phillips et al. (1967). Many enzymatic and chemical studies on lysozyme also have inductively indicated the same conclusion. However, it seems necessary to further demonstrate chemically and directly the above conclusion in order to provide a better understanding of the chemical mechanism of a lysozyme catalyzed reaction. For this purpose, it may be suitable that carboxyl -groups participating in the enzymatic activity are stepwise and homogeneously modified and their positions in the amino acid sequence are determined in connection with the change in the enzymatic activity.

Recently, the chemical modification of a carboxyl group of a protein molecule has successfully been attained, making use of water-soluble carbodiimides (Sheehan and Hess, 1955) as the carboxyl-activating and condensing reagents. Hoare and Koshland $(1966,1967)$ have first treated lysozyme with N-benzyl-N'-3dimethylpropyl carbodiimide, 1-methy1-3-(3-dimethylaminopropyl) carbodiimide and 1-cyclohexyl-3-(2-morpholinoethyl) carbodiimide, and found that eight out of eleven carboxyl groups of lysozyme were easily modified in a aqueous medium. Shibata et al. (1968) studied the modification of carboxyl groups of lysozyme with 1 ethyl-3-(3-morpholinopropyl) carbodiimide and obtained nearly the same results as those by Hoare and Koshland. However, these authors did not analyze the homogeneity of the modified products. In a protein modification, it has been often observed that an apparently stepwise modification as judged by an overall 
change in the state of functional groups does not necessarily indicate the true stepwise and homogeneous modification of the functional groups (Crestfield et al., 1963; Hayashi et al., 1968) ; the apparently stepwise modification was frequently observed as the result of an average-taking measurement on the properties of modified and unfractionated protein. The chemical modification for accumulating information about a specific functional group participating in the enzymatic activity should be followed first with a succeeding fractionation of a modified protein and then with the determination of the position of the modified group in the primary and tertiary structures.

The present paper deals with the modification of the lysozyme molecule with 1-cyclohexyl-3-(2-morpholinoethyl) carbodiimide metho-p-toluenesulfonate and the succeeding fractionation of the modified lysozyme to examine the homogeneity.

\section{EXPERIMENTAL}

\section{Materials}

Lysozyme was crystallized from hen's egg white and recrystallized four times at its isoelectric point. The substrate glycol chitin was prepared by the method reported in the previous paper (Hayashi et al., 1963). Glycine methyl ester hydrochloride was fleshly prepared. Glycinamide hydrochloride was synthesized from monochloroacetamide and concentrated ammonium hydroxide solution according to the method of Karmas and Spoerri (1952). Glycine-2- ${ }^{-14} \mathrm{C}$ was the preparation of specific activity of $9.9 \mathrm{mc} / \mathrm{mM}$ purchased from Daiichi Pharm. Co. Ltd. 1-Cyclohexyl-3-(2-morpholinoethyl) carbodiimide metho-p-toluenesulfonate (CMC) was purchased from Mann Research Laboratories Inc.

\section{Coupling of CMC with lysozyme}

To a solution of lysozyme at $\mathrm{pH} 4.7\left(0-4^{\circ} \mathrm{C}\right)$, a certain amount of CMC was added in parts over $2 \mathrm{hr}$ with adjusting possibly the $\mathrm{pH}$ of the solution to 4.7 by addition of $\mathrm{N}$ hydrochloric acid. The reaction mixture was dialyzed against $0.1 \mathrm{M}$ phosphate buffer at $\mathrm{pH} 7.5$.

\section{Coupling of glycine derivatives with lysozyme in the presence of CMC}

To a mixed solution of lysozyme and glycine derivatives $\left(0-4^{\circ} \mathrm{C}\right)$, a certain amount of CMC was added at regular intervals over several hours while maintaining the $\mathrm{pH}$ of the solution at the desired value. After converting an excess of CMC to the corresponding urea by addition of $\mathrm{N}$ acetic acid, the mixture was dialyzed against $0.2 \mathrm{M}$ phosphate buffer at $\mathrm{pH} 6.5$ containing 0.1 $\mathrm{M}$ sodium chloride. For the labelling with glycine- $-2{ }^{-14} \mathrm{C}$ methyl ester hydrochloride, the experimental conditions were chosen so that $100 \mathrm{mg}$ of the modified lysozyme contained the radioactivity of, at least, $4.5 \sim 10^{\prime} \mathrm{cpm}$.

\section{Fraction\&ion of modified lysozyme}

The modified lysozyme was fractionated on a column of BioRex 70 by linear gradient elution from $0.2 \mathrm{M}$ phosphate buffer containing $0.1 \mathrm{M}$ sodium chloride at $\mathrm{pH} 6.5$ to $0.2 \mathrm{M}$ phosphate buffer containing $0.4 \mathrm{M}$ sodium chloride at $\mathrm{pH} 6.5$. 


\section{Assay of the activity}

The activity of lysozyme was assayed by viscometry according to the method reported in the previous paper (Hayashi et al., 1963).

\section{Difference spectrum}

The difference spectrum due to the enzyme-substrate complex formation was measured according to the method described in the previous paper (Hayashi et al., 1963). For the measurement of difference spectrum of the modifled lysozyme referred to the native enzyme, the same technique was adopted. All the difference spectra were recorded with a Cary 14 spectrophotometer.

\section{Miscellaneous}

The amino acid composition was analyzed with a Hitachi amino acid analyzer, and the sedimentation constant was measured with a Spinco model E ultracentrifuge. The radioactivity of the modified lysozyme containing glycine- $2-{ }^{14} \mathrm{C}$ methyl ester residue was counted by a Ten GSL-151 liquid scintillation counter. The concentration of the lysozyme solution was determined from $\mathrm{OD}_{280}$, assuming that the molar extinction coefficient of lysozyme is 37900 (Foss, 1961).

\section{RESULTS}

\section{Coupling of CMC with lysozyme}

To $10 \mathrm{ml}$ of $0.5 \%$ lysozyme solution at $\mathrm{pH} 4.7,100 \mathrm{mg}$ of CMC was added at intervals of one hour. The reaction mixture was allowed to stand at $4^{\circ} \mathrm{C}$ for total of several hours. Aliquots of the reaction mixture were removed at intervals of two hours and the activities were assayed by viscometry. The change in the activity is shown in Fig. 1. The treatment with CMC at a room tem-

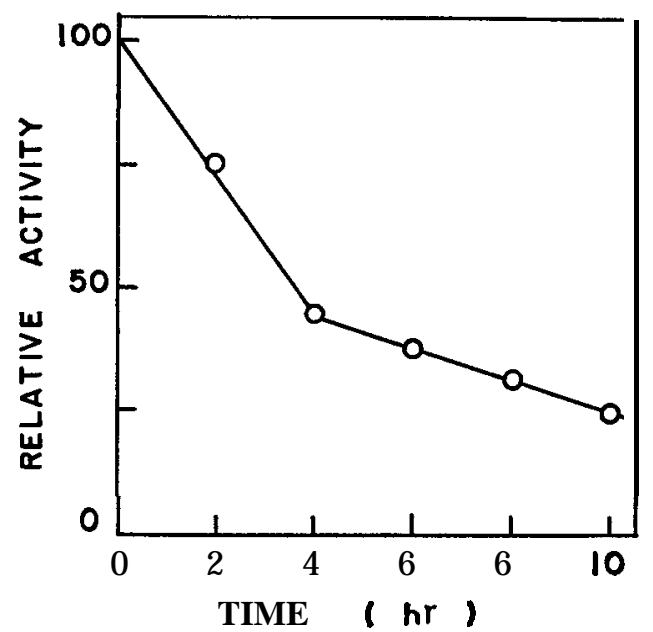

Fig. 1. Relation between remaining activity and reaction time. To $1 \mathrm{ml}$ of $0.5 \%$ lysozyme solution at $\mathrm{pH} 4.7$ and at $4^{\circ} \mathrm{C}$, each $100 \mathrm{mg}$ of CMC was added at intervals of $1 \mathrm{hr}$. The activity was measured by viscometry. 


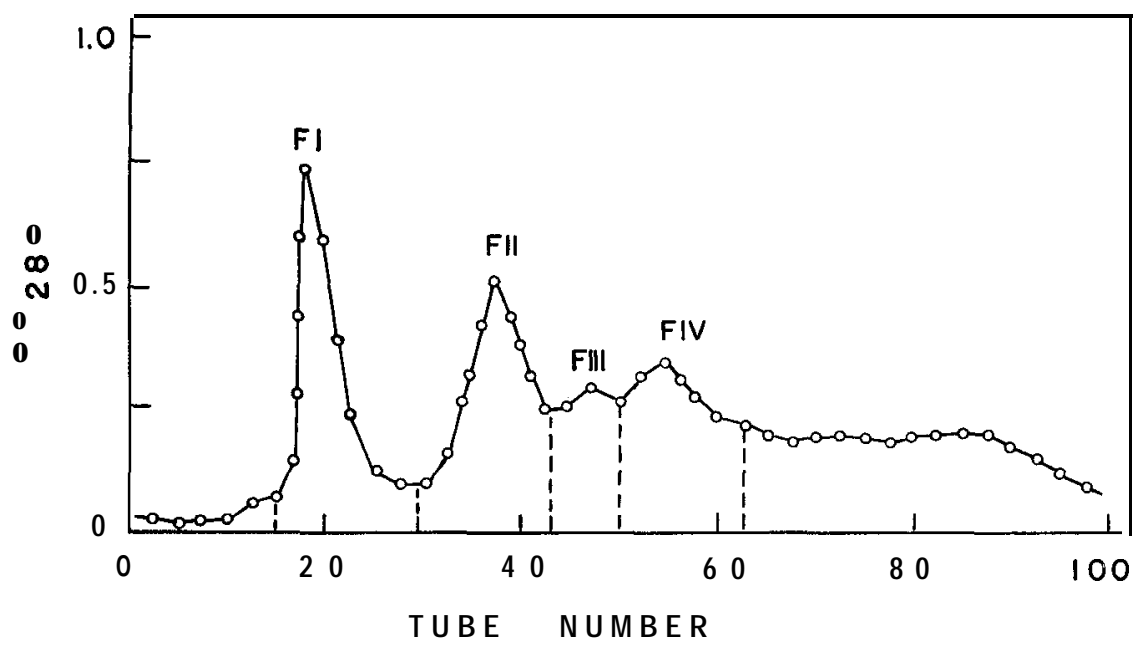

Fig. 2. Column chromatogram of modified lysozyme on BioRex 70. 50mg of modified lysozyme prepared by 4 times additions of each $100 \mathrm{mg}$ CMC was applied on a column $(1.5 \times 20 \mathrm{~cm})$ of BioRex 70. Elution was done with gradient eluent from $0.2 \mathrm{M}$ phosphate buffer, pH 6.5 containing $0.1 \mathrm{M}$ sodium chloride to $0.2 \mathrm{M}$ phosphate buffer, pH 6.5 containing $0.4 \mathrm{M}$ sodium chloride. The volume of one tube was $9.8 \mathrm{ml}$ and flow rate was $25 \mathrm{ml} / \mathrm{hr}$.

perature did not cause any loss of the activity of lysozyme. The chromatogram of modified lysozyme, which showed $27 \%$ relative activity of the native enzyme, is shown in Fig. 2. The recoveries of F I, FI, FIII and FN were 16, 19, 9 and $12 \%$, and the activities of F I, F II and FIV were $90, \mathbf{1 0}$ and $18 \%$, respectively. These results indicate that lysozyme can be modified with $\mathrm{CMC}$ at $\mathrm{pH} 4.7$ and at low temperature without the presence of a nucleophile, and that the modified lysozyme can be fractionated on a column of BioRex 70 . These modified preparations, of which carboxyl groups were modified to acyl urea, are very reactive, forming intra- and intermolecular cross-linkages with nucleophiles of the lysozyme molecule or decomposing easily in the presence of a carboxylic acid such as acetic acid.

\section{Coupling of glycine methyl ester with lysozyme}

For stabilizing the modified lysozyme, the incorporated $\mathrm{N}$-cyclohexyl- $\mathrm{N}^{\prime}-$ morpholinoethyl urea was displaced by a nucleophile glycine methyl ester. The coupling of glycine methyl ester at the carboxyl carbon of the side chain in the presence of CMC was carried out under several conditions listed in Table 1.

Table 1. Condition for the coupling reaction.

\begin{tabular}{c|c|c|c|c}
\hline \multirow{2}{*}{$\begin{array}{c}\text { Glycine methyl } \\
\text { ester } \\
\text { (g) }\end{array}$} & $\begin{array}{c}\text { Lysozyme } \\
\text { (mg) }\end{array}$ & \multicolumn{2}{|c|}{ CMC } & Chromatogram \\
\cline { 3 - 4 } & & (mg) & $\begin{array}{c}\text { Interval } \\
\text { (hr) }\end{array}$ & \\
\hline 0.2 & 100 & $50 \times 4$ & 1 & Fig. 3-1 \\
2.5 & 100 & $50 \times 4$ & 1 & $3-2$ \\
5.0 & 100 & $50 \times 4$ & 2 & $3-3$ \\
2.5 & 100 & $100 \times 4$ & 1 & $3-4$ \\
\hline
\end{tabular}




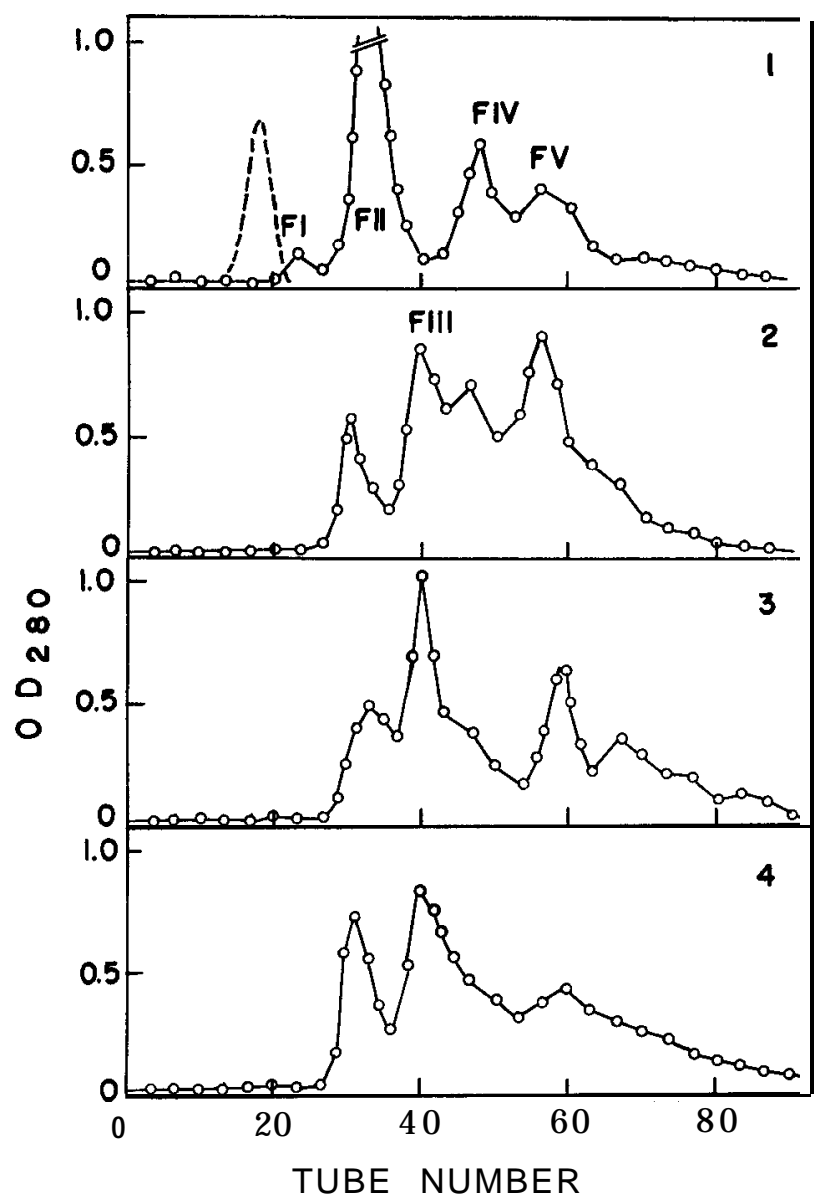

Fig. 3. Column chromatogram of lysozyme modified by glycine methyl ester. The conditions for preparation of modified lysozymes were listed in Table 1. Sample : 100 $\mathrm{mg}$, column size $: 1.5 \times 24 \mathrm{~cm}$, one tube $: 9.8 \mathrm{ml}$, flow rate $: 20 \mathrm{ml} / \mathrm{hr}$. Broken line represents the position of the native lysozyme. The activities of FII,FIII,FIV and FV in Fig. 3-2 were $80,72,72$ and $58 \%$, respectively.

The modified lysozymes were fractionated on a column of BioRex 70. As seen in Fig. 3, the modified lysozyme exhibits complex patterns. The extent of modification was influenced rather by the amount of glycine methyl ester hydrochloride than that of CMC. The modified lysozymes, contrary to the case of modification without glycine methyl ester hydrochloride, showed considerably high activity. The modification on a preparative scale displayed nearly the same result as on an analytical scale.

The $\mathrm{pH}$-dependence of coupling reaction of glycine methyl ester

To $10 \mathrm{ml}$ of $0.5 \%$ lysozyme solution containing $100 \mathrm{mg}$ of glycine methyl ester hydrochloride at a given $\mathrm{pH}$ and $0^{\circ} \mathrm{C}, 25 \mathrm{mg}$ of CMC was added eight times at intervals of $30 \mathrm{~min}$. The reaction mixture was allowed to stand for another one 
K. Hayashi et al.

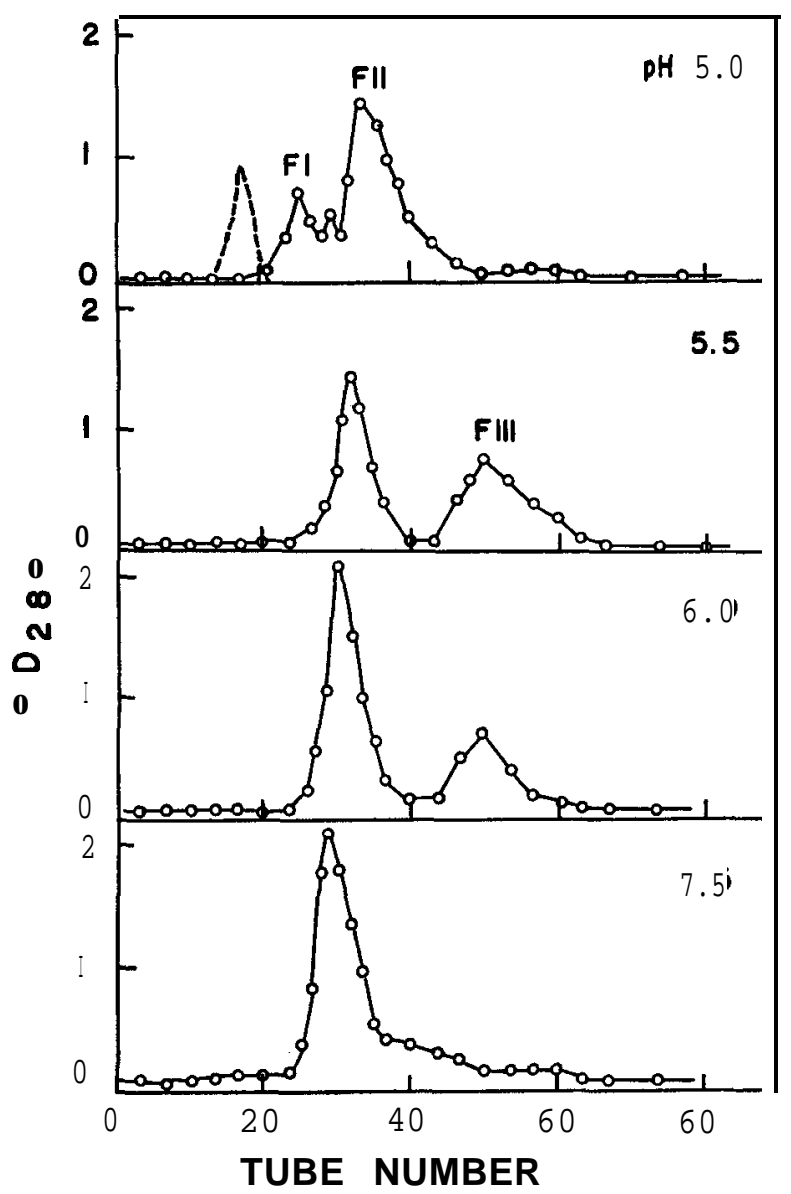

Fig. 4. The pa-dependence of modification. Conditions for chromatography were the same ast hose for the above. Broken line represents the position of the native lysozyme.

Table 2. Amino acid composition of FII in Fig. 4-3.

\begin{tabular}{c|c|c}
\hline & Found & Theory $^{\text {a) }}$ \\
\hline Asp & 21.30 & 21 \\
& & 7 \\
Thr & 10.07 & 10 \\
Sidn & 5.61 & 6 \\
Pro & 1.46 & 2 \\
Gly & 12.62 & $\mathbf{1 2}$ \\
Ala & 12.00 & 12 \\
Mael & & 6 \\
Leu & 7.76 & 2 \\
Ileu & 5.34 & 8 \\
Tyys & 2.96 & 6 \\
\hline
\end{tabular}

a) Canfield (1963). 
hour after the final addition of CMC. Each modified lysozyme was fractionated. The chromatograms are shown in Fig. 4. The extent of modification apparently decreased with a rise in the $\mathrm{pH}$ value of the reaction mixture. Above $\mathrm{pH} 7.0$, only FII was formed. The amino acid composition of FII in Fig. 4-3 (pH 6.0) is shown in Table 2. From this result, it is obvious that FII is a fraction modified with a single glycine methyl ester.

\section{Coupling of glycinamide with lysozyme}

In the series of the present experiments, the fractionation of modified lysozyme and the separation of a peptide containing a modified side chain carboxy1 group were attempted on the basis of diminution of the negative charges due to the modification. The spontaneous hydrolysis of glycine methyl ester incorporated to lysozyme will cause some difficulty. To avoid this trouble, it was attempted to introduce glycinamide hydrochloride to the modification in place of glycine methyl ester hydrochloride. Coupling of glycinamide with lysozyme was carried out according to the conditions listed in Table 3 . The amount of F I and FII in Fig. 5-1 diminished gradually with increase in the amount of $\mathrm{CMC}$, and the amount of other fractions, which were eluted late and seemed to be highly modified, was concurrently increased. The most dominant factor which controlled the extent of modification was the amount of glycinamide hydrochloride added. As can be seen in Fig. 5-1, the native lysozyme disappeared already at early stages of the coupling reaction. This implied that a certain side chain carboxyl group was easily modified by the coupling reaction.

Table 3. Condittions for the coupling reaction of glycinamide.

\begin{tabular}{c|c|c|c|c}
\hline \multirow{2}{*}{$\begin{array}{c}\text { Glycinamide } \\
\text { (mg) }\end{array}$} & \multirow{2}{*}{$\begin{array}{c}\text { Lysozyme } \\
\text { (mg) }\end{array}$} & \multicolumn{2}{|c|}{ CMC } & \multirow{2}{*}{ Chromatogram } \\
\cline { 3 - 4 } & & $\begin{array}{c}\text { (mg) } \\
\text { (mg) }\end{array}$ & $\begin{array}{c}\text { Interval } \\
\text { (hr) }\end{array}$ & \\
\hline 200 & 500 & $50 \times 2$ & 0.5 & $5-1$ \\
200 & 500 & & 1.0 & $5-2$ \\
200 & 500 & $50 \times 6$ & 1.0 & $5-3$ \\
200 & 500 & $50 \times 8$ & 1.0 & 5 \\
200 & 1000 & $50 \times 8$ & 1.0 & 5 \\
\hline
\end{tabular}

\section{Characterization of some modified lysozyme}

The fractions, FII, FIII and FIV in Figs. 5-1 and 5-3 were rechromatographed and the main fractions were characterized.

(1). Amino acid composition: The amino acid compositions of the fractions are shown in Table 4. All the fractions show an enrichment of glycine content; $F \Pi$, FIII and FIV contain one, two and two carboxyl groups modified, respectively. (2). Relative activity : The relative activity of FII, FIII and FIV were 78, 66 and $54 \%$, respectively. This means that two carboxyl groups, which are preferentially modified, are not participating in the activity of lysozyme.

(3). The lysozyme-substrate complex: The abilities of FII,FII and FIV to form the complex with the substrate glycol chitin were 48,46 and $40 \%$, respectively, of that of the native lysozyme.

(4). The difference spectrum of FII referred to the native lysozyme is shown in Fig. 6. The magnitude of the difference molar extinction coefficient, $\Delta \varepsilon_{293}$, 


\section{K. Hayashi et al.}

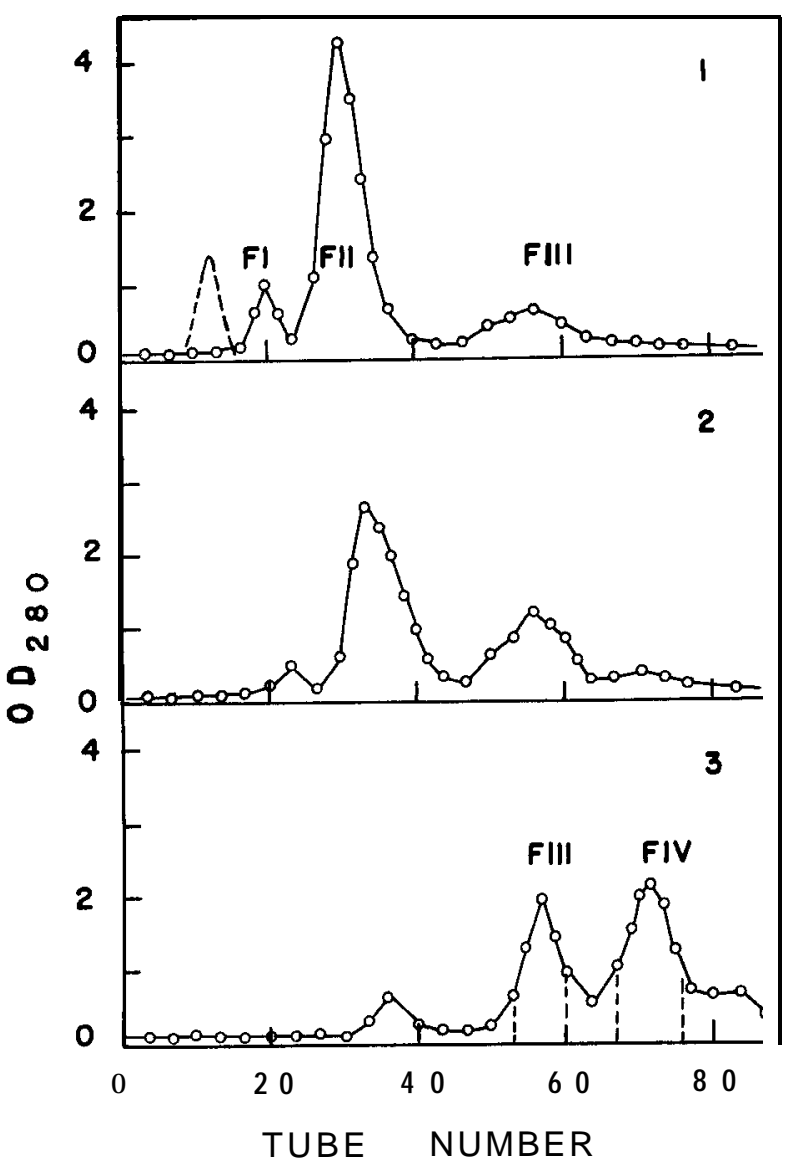

Fig. 5. Chromatogram of lysozyme modified by glycinamide. For conditions for prep aration of lysozymes modifiied, see Table $3.200 \mathrm{mg}$ of lysozyme modified, was loaded on a column $(1.8 \times 48 \mathrm{~cm})$. One tube $: 10.8 \mathrm{ml}$, flow rate $: 17 \mathrm{ml} / \mathrm{hr}$. The activites of FI, FII and F III in Fig. 5-1 were 90, 57 and $43 \%$, respectively. Broken line shows the position of the native enzyme.

Table 4. Amino acid compositions of FII, FIII and FN in Figs. 5-1 and 5-3.

\begin{tabular}{|c|c|c|c|c|}
\hline & FII & F III & $\mathrm{F}_{\mathrm{IV}}$ & Theory ${ }^{a)}$ \\
\hline $\begin{array}{l}\text { Asp } \\
\text { Thr }\end{array}$ & $\begin{array}{r}21.00 \\
6.50\end{array}$ & $\begin{array}{r}21.00 \\
6.66\end{array}$ & 21.00 & $\begin{array}{r}21 \\
7\end{array}$ \\
\hline $\begin{array}{l}1 \mathrm{nr} \\
\text { Ser }\end{array}$ & $\begin{array}{l}0.50 \\
9.54\end{array}$ & $\begin{array}{l}0.00 \\
9.21\end{array}$ & 0.42 & $\begin{array}{r}7 \\
10\end{array}$ \\
\hline Glu & 5.30 & 5.34 & $\begin{array}{l}9.41 \\
5.35\end{array}$ & $\begin{array}{c}10 \\
5\end{array}$ \\
\hline Gly & 12.84 & 14.26 & & 12 \\
\hline Ala & $\begin{array}{l}11.69 \\
\end{array}$ & 11.86 & $14.0 B$ & 12 \\
\hline Val & 4.92 & - & 5.31 & 6 \\
\hline Met & 2.08 & 2.06 & 2.15 & 2 \\
\hline Ileu & 5.70 & 5.45 & 6.04 & 6 \\
\hline Leu & 8.29 & 8.63 & 8.32 & 8 \\
\hline Tyr & 3.19 & 3.35 & & 3 \\
\hline $\begin{array}{l}\text { Phe } \\
\text { Phe }\end{array}$ & 3.01 & 3.36 & 3.00 & 3 \\
\hline
\end{tabular}

a) Canfield (1963). 


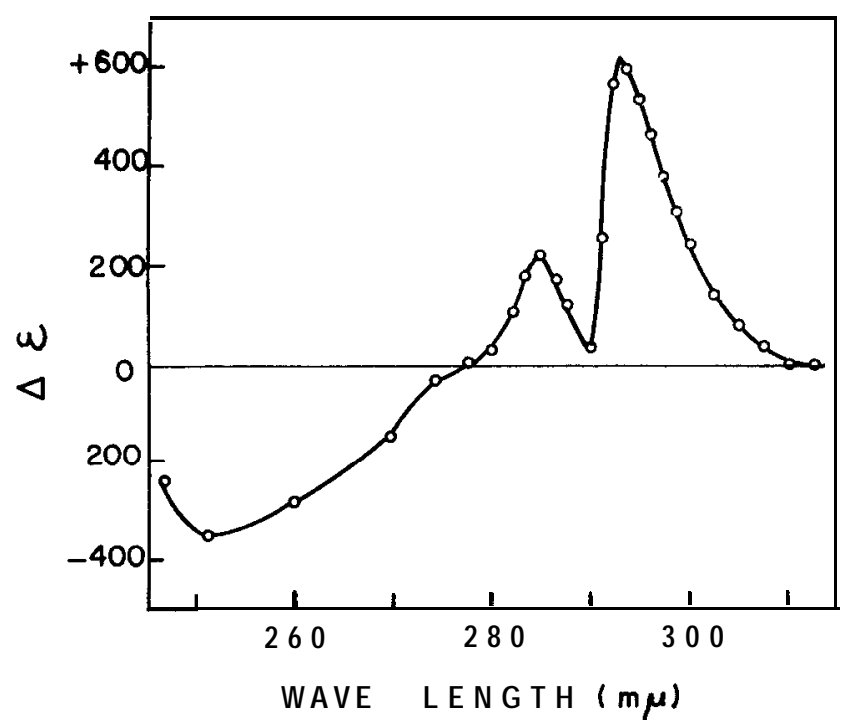

Fig. 6. Difference spectrum of FII referred to the native lysozyme.

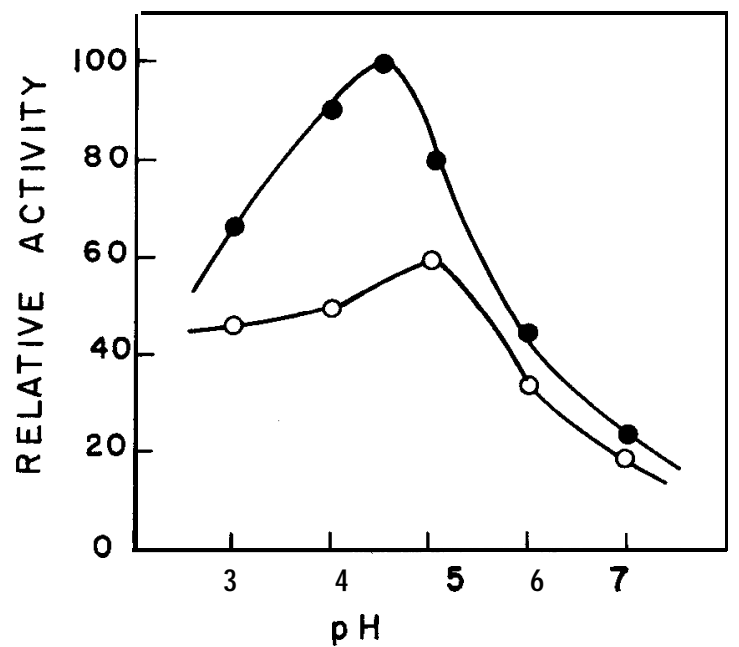

Fig. 7. The pH-dependence of the activity of F II and the native lysozyme. .$:$ the native, 0 : Fi I.

was of the order of 600 . This result indicates that some tryptophan residues were masked because of a concomitant conformational change and/or by the glycinamide residue incorporated.

(5). The sedimentation constant of the $\mathrm{F} I I$ solution $(1 \%)$ at $20^{\circ} \mathrm{C}$ and at $\mathrm{pH} 5.6$ was found to be $1.57 \mathrm{~S}$. This indicates that there is neither aggregation nor intermolecular cross-linkage in the modified lysozyme molecule.

(6). The pH-activity profile of FII: A greater loss of the activity of FII was seen around $\mathrm{pH} 4.0$ where the maximum of the activity of the native lysozyme appeared, as shown in Fig. 7. 
(7). Stability of FII: The stability of FE measured by the remaining activity on incubation at $100^{\circ} \mathrm{C}$ was increased 1.5 times as compared with the native lysozyme. The stability of FII in a concentrated urea solution was nearly the same as that of the native enzyme.

(6). The radioactivity of incorporated glycine $-2-{ }^{14} \mathrm{C}$ residue distributed in parallel to the $\mathrm{OD}_{280}$ in chromatogram.

\section{DISCUSSION}

The modification of carboxyl groups in the lysozyme molecule with CMC in the presence of a glycine derivative exhibited a sharp pa-dependence. The extent of the modification decreased in a medium at high $\mathrm{pH}$; above $\mathrm{pH} 7.0$, only fraction F II with contained one carboxyl group modified was formed even in the presence of a large excess of CMC and glycine derivative. Therefore, neutral media may be preferable for obtaining a lysozyme preparation with a low extent of the modification. The concentration of either glycine methyl ester hydrochloride or glycinamide hydrochloride in the reaction mixture affected, contrary to expectation, the extent of the modification. This might be caused by the nature of the intermediate, the acyl urea, of the reaction. No difference in the extent of the modification was observed between glycine methyl ester hydrochloride and glycinamide hydrochloride.

The fraction FII appeared in most case with a good separation from other fractions upon chromatography. The content of FII in the modified lysozyme preparation diminished with the progress of the reaction, accompanying the concurrent increase in the amounts of reaction products highly modified. When glycine- $2{ }^{-14} \mathrm{C}$ methyl ester hydrochloride was used, it was found that the $\mathrm{OD}_{280}$ of FII in the chromatogram was completely proportional to the radioactivity. The number of carboxyl group modified in FII was calculated to be one from measurement of the radioactivity.

Thus, it is obvious that a certain carboxyl group of lysozyme coupled preferentially with glycine dreivatives in the presence of CMC. The fraction FII and $\mathrm{FN}$ were formed when the reaction proceeded further, and the amount of FII had consequently diminished. FIII and FN may contain a different carboxyl groups modified, together with a certain carboxyl group as common one. Therefore, it is presumed that two or three out of eleven carboxyl groups of the lysozyme molecule can rapidly be modified by a glycine derivative with the aid of CMC.

The activity of the lysozyme preparation, in which carboxyl groups were modified, was found to be of the order of 40-60\% of the native enzyme. Obviously, the carboxyl groups modified rapidly did not participate in the activity of lysozyme.

Thus, the modification of lysozyme appeared to proceed stepwise in early stages of the reaction. Since the fractionation method adopted in the present experiment was based upon the change in the amount of net charge of the lysozyme molecule, there remains a doubt that FII,FIII or FN may be the mixture of several molecular species, which are modified at different positions 
in the lysozyme molecule. This cannot be solved simply by chromatographic technique. For the determination of the homogeneity of each fraction, it is absolutely necessary to determine the positions of the modified carboxyl groups in the amino acid sequence.

\section{REFERENCES}

Blake, C. C. F., Johnson, L. N., Mair, G. A., North, A. C. T., Phillips, D. C. and Sarma, V. R. 1967. Crystallographic studies of the activity of hen egg-white lysozyme. Proc. Royal Soc. B $167: 378-388$.

Canfield, R. E. 1963. The Amino Acid Sequence of Egg White Lysozyme. J. Biol. Chem. 238: 2698-2707.

Crestfield, A. M., Stein, W. H. and Moor, S. 1963. Properties and Conformation of the Histidine Residues at the Active Site of Ribonuclease. J. Biol. Chem. 238 : 2421-2428.

Foss, J. G. 1961. Hydrophobic Bonding and Conformational Transitions in Lysozyme, Ribonuclease and Chymotrypsin. Biochim. Biophys. Acta 47: 569-579.

Hayashi, K., Imoto, T. and Funatsu, M. 1963. The Enzyme-substrate Complex in a Muramidase Catalyzed Reaction. I. Difference Spectrum of Complex. J. Biochem. 54: 381-387.

Hayashi, K., Shimoda, T., Imoto, T. and Funatsu, M. 1968. Iodination of Lysozyme. II. Reactivity and Position of Tyrosine Residues. J. Biochem. 64: 365-370.

Hoare, D. G. and Koshland Jr. D. E. 1966. A Procedure for the Selective Modification of Carboxyl Groups in Proteins. J. Am. Chem. Soc. 88: 2057-2058.

- 1967. A Method for the Quantitative Modification and Estimation of Carboxylic Acid Groups in Proteins. J. Biol. Chem. 242: 2447-2453.

Horinishi, H., Nakaya, K., Tani, A. and Shibata, K. 1968. States of Amino Acid Residues in Protein. J. Biochem. 63: 41-50.

Karmas, G. and Spoerri, P. E. 1952. The Preparation of Hydroxypyrazines and Derived Chloropyrazines. J. Am. Chem. Soc. 74: 1580-1584.

Sheehan, J. C. and Hess, G. P. 1955. A New Method of Forming Peptide Bonds. J. Am. Chem. Soc. 77: 1067-1068. 